\title{
Direct Current Charger Hardware Platform Design
}

\author{
Yu Zhang \\ College of Automotive Engineering, Shanghai University of Engineering Science, Shanghai, China \\ Email:2656247837@qq.com
}

How to cite this paper: Zhang, Y. (2018) Direct Current Charger Hardware Platform Design. Open Access Library Journal, 5: e4593.

https://doi.org/10.4236/oalib.1104593

Received: April 10, 2018

Accepted: April 25, 2018

Published: April 28, 2018

Copyright $\odot 2018$ by author and Open Access Library Inc.

This work is licensed under the Creative Commons Attribution International License (CC BY 4.0).

http://creativecommons.org/licenses/by/4.0/

\section{(c) (i) Open Access}

\begin{abstract}
In order to reduce the pollution caused by fuel vehicles to the environment, electric vehicles are becoming the means of transportation. The replacement of fuel vehicles by electric vehicles is a future trend. Based on practical requirements, a $120 \mathrm{~kW}$ direct current charger has been designed. Taking the MK60DN512 as the core controller, a direct current charger control system is designed and implemented. The overall solution of the direct current charger control system is designed. According to the functional requirements of the direct current charger, a system hardware platform is built based on embedded technology. The hardware mainly consists of MK60DN512 microcontroller, start/reset circuit, JTAG download/debugging circuit, clock circuit, minimum system power supply, output voltage sampling and signal conversion circuit, output current sampling and signal conversion circuit, AC relay control circuit and temperature detection circuit.
\end{abstract}

\section{Subject Areas}

Electric Engineering

\section{Keywords}

DC Charger, $120 \mathrm{~kW}$, The New GB, Parallel Current Sharing, Power Module

\section{Introduction}

Facing the increasingly severe challenges of the environment, energy and climate change, vigorously developing new energy industries and gradually promoting the transformation of transportation energy through the development of new energy, vehicles are the main ways to achieve sustainable development of the entire automotive industry. After the exploratory period of early blooming flowers, new energy vehicles have formed a consensus in the international arena and 
gradually realize the electrification of automobiles. The development of electric vehicles is its strategic focus and general trend. However, due to the slow construction of charging facilities, the ratio of electric vehicles and chargers, a serious imbalance, the promotion of electric vehicles has been limited [1].

According to statistics from the China Association of Automobile Manufacturers, domestic sales of new energy vehicles in 2015 increased 3.4 times year-on-year, reaching 330,000 vehicles. However, the construction of the charger has lagged far behind. By the end of 2015, 3600 charging stations and 49,000 public chargers have been built in the country. The ratio of chargers and electric vehicles is about 1:9, according to the charger and electric vehicle 1:1, the configuration standards, the huge gap in the number of chargers.

Direct current charging method is also known as "fast charge". Direct current chargers use this method to directly charge EV battery packs. The direct current charger input is $380 \mathrm{~V} \mathrm{AC}$ and the output is adjustable DC. This kind of charging speed is fast, but it will affect the life of the battery pack. Direct current chargers are mostly built in large charging stations.

AC charging method is also known as "slow charge." The AC charger uses this method to charge the onboard charger of the electric vehicle. It does not provide any power output itself, but only acts as a control switch [2].

In this way, the charging speed is slow and cannot meet some special charging requirements, but it can effectively protect the battery pack. AC chargers are mostly built in supermarkets, parking lots and other public areas.

The electric vehicle direct current charger is a power supply device that is fixedly installed outside the electric vehicle and provides a high-power direct current charging function for the electric vehicle battery (Figure 1).

\section{Direct Current Charger Control System Design}

\subsection{Charger Charging Principle}

A direct current charger is a charging device that directly charges an electric automobile power battery through an AC grid. Because of its faster charging speed, people in the industry also call it "fast charging". The AC charger is different.

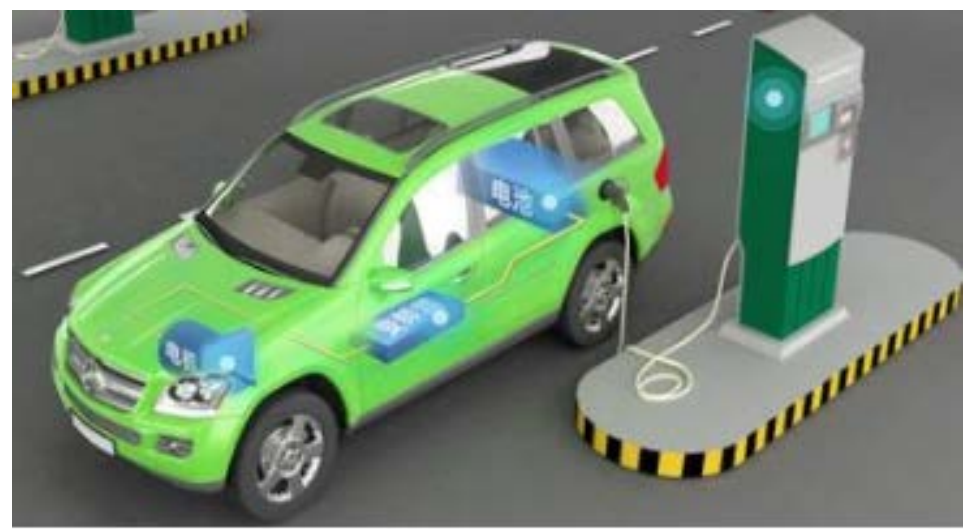

Figure 1. Connection diagram of dc charger and electric vehicle. 
The AC charger is a device that charges the battery by means of an electric vehicle on-board charger through the AC grid. Because the charging speed is slower than that of the DC charger, it is called "slow charging" [3]. The difference between the charging modes of the two chargers can be simply summarized as follows: The direct current charging device can directly charge the battery of the electric vehicle, and the AC charger needs to use the on-board charger to charge the battery indirectly. In addition, the two charging methods also differ greatly in charging speed. When fully charging an electric car with an average battery capacity (a charge process from 0\% to 100\%), using an AC charger takes about eight hours to complete. When using a direct current charger to fully charge, it only takes two to three hours.

\subsection{Charging Control Principle}

The charging control function is the most basic function of the direct current charger system. The direct current charging pile is powered by three-phase AC power to provide a safe and reliable DC charging function for the electric vehicle. Specifically including: The charger shall provide low voltage auxiliary power for the electric vehicle, which is used to provide power for the battery management system of the electric vehicle during the charging process. The power supply voltage shall be $12 \mathrm{~V}$ direct current; the charging pile shall be compatible with the old and new national standard protocol, and be automatically connected and performed after inserting the gun. Charging control, after the completion of the charging should be able to automatically disconnect; in the charging process, the charging pile dynamically adjusts the charging parameters based on the data provided by the battery management system, perform the appropriate actions to complete the charging process. The entire charging process includes four phases, a handshake phase, a charging parameter configuration phase, a charging phase, and a charge termination phase. Each phase of the BMS will send a different message. After receiving the message, the microcontroller performs a corresponding action, for example, controlling the closing of the contactor and controlling the output voltage and current of the direct current output unit. After that, the microcontroller needs to be charged according to non-vehicle. Machine and battery management system communication protocol reply corresponding message.

\subsection{Overall Scheme Design of Direct Current Charger Control System}

In Figure 2, the specific working principle: the contactor controls the on and off of $380 \mathrm{~V}$ AC power, the AC power meter is connected to the output terminal of the contactor, and the direct current charger control board reads the energy meter data in real time through RS232 communication, which is used by the user. Electricity is calculated. The output terminal of the AC power meter is connected to the DC output unit. The DC charger control board sends commands 
DC charger

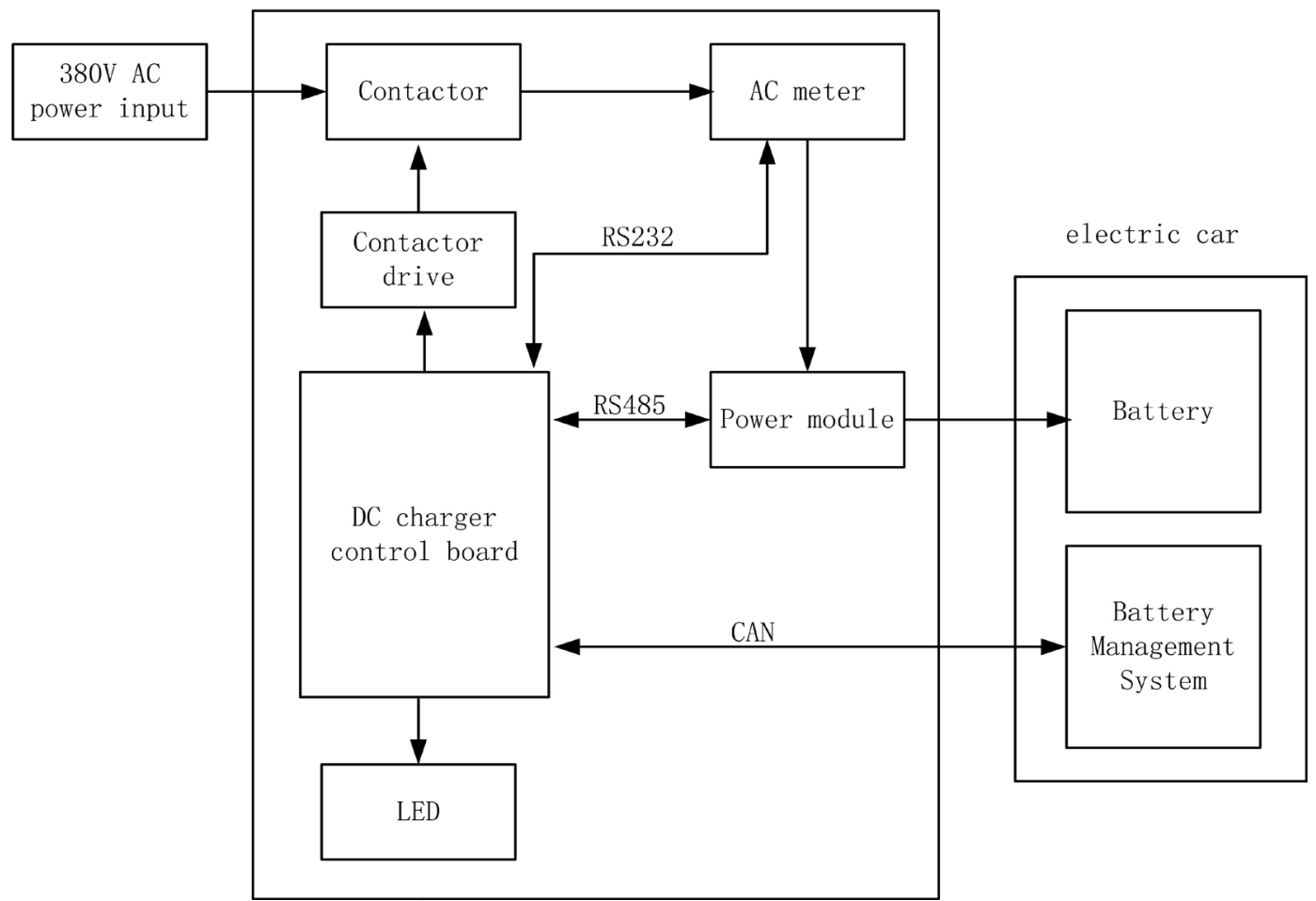

Figure 2. Structure diagram of dc charger control system.

to the power supply module through RS485 communication to control the output voltage and current. The DC output unit is directly connected to the battery pack of the electric vehicle, and the battery pack is quickly Charging, the battery management system sends the battery pack parameters to the DC charger control board via the CAN bus. After receiving the message, the DC charger control board parses the message and adjusts the voltage and current in time. During the charging process, the AC contactor can be controlled by the DC charger control board, or it can be directly closed by the forced closing button. After receiving the voltage and current requirements sent by the BMS, the DC charger control board compares the current value with the current value returned by the power module after receiving the voltage and current requirements sent by the BMS. If the controller does not adjust the current, the controller will re-send the command to the power supply, Module. The message sent by the BMS battery management system through the CAN bus, part of the DC charger control board is used for charge control, and the other part is used to analyze the cell voltage information in the message.

\section{Control Board Hardware Platform Design}

\subsection{Control Board Hardware Overall Design}

Direct current charger control board in hardware by the MK60DN512 microcontroller, crystal, RS485 external circuit, JTAG download circuit, reset circuit, power circuit, CAN transceiver, output voltage sampling, output current sam- 
pling, relay control circuit and temperature detection circuit The CAN transceiver of the control board realizes the communication between the DC charger and the battery management system of the electric vehicle. The RS485 circuit is an external circuit for the communication between the control board and the power supply module. It is mainly used for the control board to issue commands to the power supply module and the receiving power supply module. The returned command; the output voltage sampling and signal conversion circuit and the output current sampling and signal conversion circuit perform real-time sampling of the output voltage and current of the DC charger power module, and is converted into a voltage of 0 to $3.3 \mathrm{~V}$ that is identifiable by the MK60DN512 chip., MK60DN512 through the A/D converter to get the output voltage and current value; relay control circuit for controlling the closing and opening of the relay, close the relay when charging is needed, disconnect the relay when stopping charging; temperature detection circuit for charging The temperature of the internal power module prevents over-temperature; The circuit provides the clock beats for the chip; the $3.3 \mathrm{~V}$ obtained by the power circuit conversion mainly supplies power to the chip; the other $12 \mathrm{~V}$ and $5 \mathrm{~V}$ circuits are powered by the power supply outside the control board; the JTAG download circuit is used for the software writer to the chip and can also be used for software Debug debugging [4].

\subsection{MK60DN512 Chip Introduction}

Taking into account the complexity of the direct current charger and the need for future modifications or functional extensions, the traditional 8-bit microcontrollers are slower, less accurate, and have poorer expansion capabilities, making it difficult to meet our design requirements. Therefore, this vehicle terminal hardware system selects Microcontroller chip MK60DN512 developed by Freescale based on ARM Cortex-M3 core. The chip has advanced core design and rich peripherals. The circuit of the MK60DN512 chip is shown in Figure 3, the main chip MK60DN512 is clocked at $72 \mathrm{MHz}$. Its CPU core (Cortex-M3) consists of a 32-bit RISC (Reduced Instruction Set Computer) processor, a 64K byte of Flash program memory and $20 \mathrm{~K}$ bytes of data. SDRAM, single-cycle multiplication and hardware division, can reach $1.25 \mathrm{DMips} / \mathrm{MHz}$ in 0 wait cycle access of the memory. Rich Peripheral Interface: Supports various communication methods such as USART, I2C, SPI, CAN, USB, etc., which are sufficient to meet various complex needs, DMA, timer and PWM control, ADC, temperature sensor, etc. Control all occasions can meet the requirements.

\subsection{Output Voltage Sampling and Signal Conversion Circuit}

The output voltage sampling and signal conversion circuit converts the strong electric signal output by the power supply module into a $0-3.3 \mathrm{~V}$ weak electric signal that can be identified by the MK60DN512 chip A/D module, and isolates the main power circuit and the control circuit. The output voltage sampling and signal con- 
version circuit uses the Hall voltage sensor WHV05AS5S6 and a one-to-one in-phase operational amplifier. Output voltage sampling and signal conversion circuit shown in Figure 4.

\subsection{Output Current Sampling and Signal Conversion Circuit}

The output current sampling is mainly realized by a Hall current sensor. The

\begin{tabular}{|c|c|c|c|}
\hline & & & U7C \\
\hline PTA24 & Text & 75 & \\
\hline PTA25 & Text & 76 & 424 \\
\hline PTA26 & Text & 77 & $\begin{array}{l}\text { IA25 } \\
\text { TA26 }\end{array}$ \\
\hline PTA27 & Text & 78 & \\
\hline PTA28 & Text & 79 & \\
\hline$\overline{\text { PTA29 }}$ & Text & 80 & РТА28 \\
\hline IICO SC & & 81 & PTA29 \\
\hline IICO SL & & 82 & PBO/LLWU_ \\
\hline PB2 & Text & 83 & \\
\hline PB3 & Text & 84 & $\begin{array}{l}\text { PB2 } \\
\text { PR3 }\end{array}$ \\
\hline PB4 & Text & 85 & PB3 \\
\hline PB5 & Text & 86 & $\begin{array}{l}\text { PB4 } \\
\text { PR5 }\end{array}$ \\
\hline PB6 & Text & 87 & B5 \\
\hline PB7 & Text & 88 & $\begin{array}{l}\text { B66 } \\
\text { PR7 }\end{array}$ \\
\hline PB8 & Text & 89 & $\begin{array}{l}\text { PB7 } \\
\text { PR8 }\end{array}$ \\
\hline PB9 & Text & 90 & \\
\hline PB10 & Text & 91 & \\
\hline PB11 & Text & 92 & PB10 \\
\hline PB16 & Text & 95 & 311 \\
\hline PB17 & Text & 96 & B16 \\
\hline CANO & & 97 & PB17 \\
\hline CANO & & 98 & PB18 \\
\hline PB20 & Text & 99 & 319 \\
\hline PB21 & Text & 100 & 320 \\
\hline PB22 & Text & 101 & 321 \\
\hline PB23 & Text & 102 & PB22 \\
\hline $\mathrm{PCO}$ & Text & 103 & $\begin{array}{l}\text { PB23 } \\
\text { PCO }\end{array}$ \\
\hline PC1 & Text & 104 & 0 \\
\hline $\mathrm{PC} 2$ & Text & 105 & 1/LLWU_P \\
\hline RXD1 & RXD1 & 106 & PC3/L \\
\hline TXD1 & TXD1 & 109 & 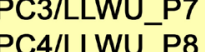 \\
\hline
\end{tabular}

\begin{tabular}{|c|c|c|}
\hline P15 144 & Text & PD15 \\
\hline PU15 $\overline{143}$ & Text & $\overline{P D 14}$ \\
\hline PD14 142 & Text & PD13 \\
\hline PD13 141 & Text & PD12 \\
\hline PD12 140 & Text & PD11 \\
\hline PD11 $\frac{140}{139}$ & Text & CS-485-1 \\
\hline PD10 $\frac{109}{138}$ & Text & TXD5 \\
\hline PD9 $\frac{138}{137}$ & Text & $\frac{\text { IADS }}{\text { RXD5 }}$ \\
\hline PD8 $\frac{131}{136}$ & Text & TXD0 \\
\hline PD7 $\frac{136}{133}$ & Text & $\frac{1 \mathrm{RDO}}{\mathrm{RXD0}}$ \\
\hline LLWU_P15/PD6 $\frac{133}{132}$ & Text & $\frac{\text { RXDO }}{\text { PD5 }}$ \\
\hline PD5 $\frac{132}{131}$ & & PD5 \\
\hline LLWU_P14/PD4 $\frac{131}{130}$ & Text & PD4 \\
\hline PD3 $\frac{130}{129}$ & TXD2 & $\overline{T X D 2}$ \\
\hline LLWU_P13/PD2 $\frac{129}{128}$ & RXD2 & RXD2 \\
\hline PD1 $\frac{128}{127}$ & Text & PD1 \\
\hline LLWU P12/PD0 127 & Text & PD0 \\
\hline PC19 126 & Text & $\mathrm{PC} 19$ \\
\hline PC19 & Text & PC18 \\
\hline PC18 124 & TXD3 & TXD3 \\
\hline PC16 123 & RXD3 & RXD3 \\
\hline PC15 $\overline{120}$ & TXD4 & TXD4 \\
\hline PC15 119 & RXD4 & RXD4 \\
\hline PC14 118 & Text & $\mathrm{PC} 13$ \\
\hline $\begin{array}{l}\text { PC13 } \\
\text { PC12 }\end{array}$ & Text & PC12 \\
\hline PC12 116 & Text & IIC1 SDA \\
\hline PC10 115 & Text & $\overline{I I C 1 S C L}$ \\
\hline PC9 114 & Text & PC9 \\
\hline PC8 113 & Text & $\mathrm{PC} 8$ \\
\hline PC7 112 & & SPIO SIN \\
\hline LLWU P10/PC6 & & SPIO SOUT \\
\hline LLWU_P9/PC5A 110 & & SPIO SCLK \\
\hline
\end{tabular}

Figure 3. MK60DN512 Chip circuit diagram.

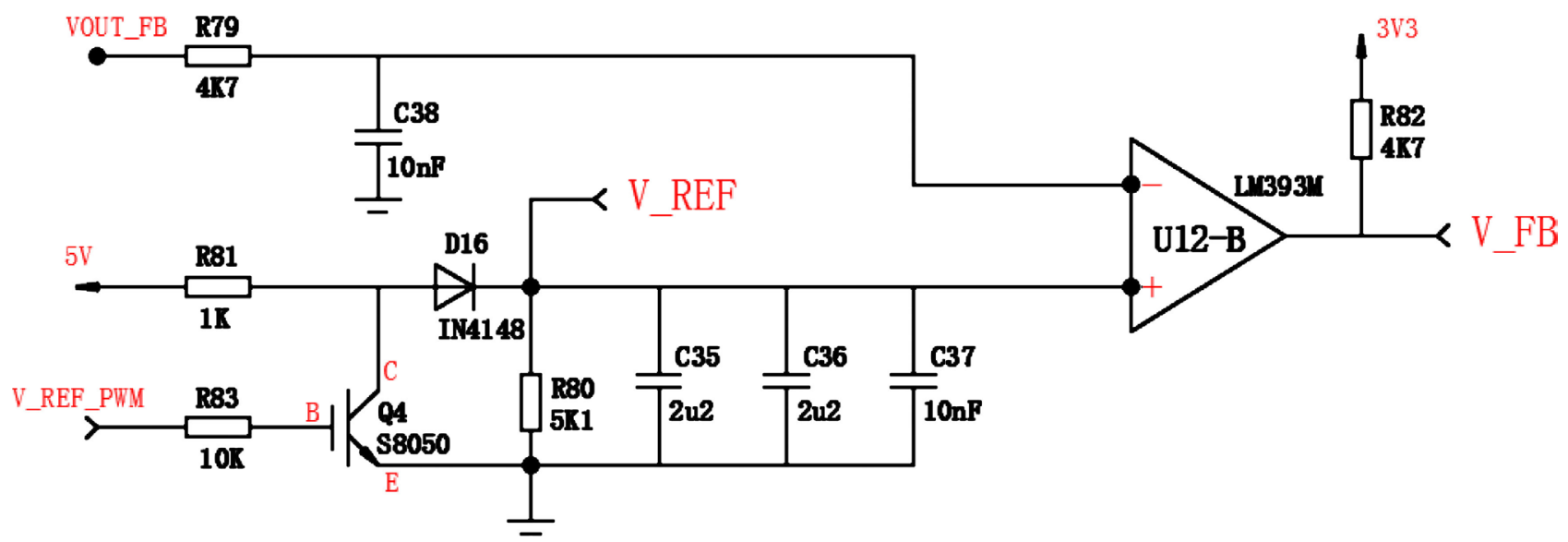

Figure 4. Output voltage sampling and signal conversion circuit. 

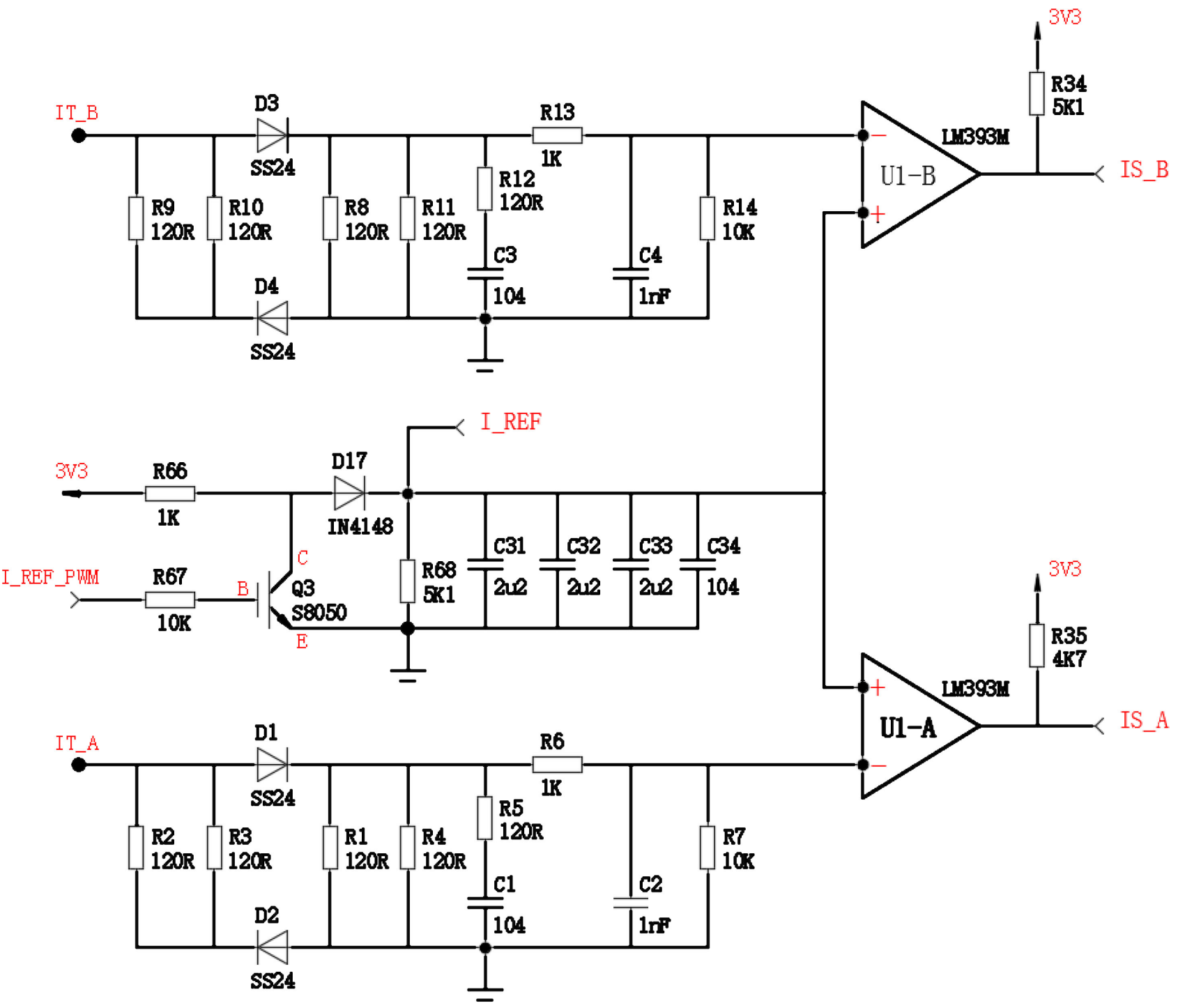

Figure 5. Output current sampling and signal conversion circuit.

Hall current sensor adopts BYD Company's BSY2-100IOV2L, which has the advantages of good linearity, high precision, wide frequency band, and strong isolation. The BSY2-100IOV2L has a rated input current of 0 to $100 \mathrm{~A}$, a rated output voltage of $4 \mathrm{~V}$, and a power supply voltage of $\pm 12 \mathrm{~V}$ to $\pm 15 \mathrm{~V}$, The specific circuit of the output current sampling and signal conversion circuit is shown in Figure 5.

\section{Conclusion}

In short, firstly the direct current test system is turned on, then the charger to start charging is operated, and the CAN data logger is used to record the message of the entire charging process. After continuous debugging and protocol analysis, the communication that meets the protocol requirements is finally realized. In the process, some messages are shown in Figure 6. In the message, the charge handshake phase, charging parameter configuration 


\begin{tabular}{|c|c|c|c|c|c|c|c|c|c|c|c|}
\hline 55341.11 & $0 \times 1801 f 456$ & $\mathrm{RxDX}$ & 8 & 00 & ff & ff & ff & ff & ff & ff & ff \\
\hline 55347.21 & $0 \times 1$ cec 56 f 4 & $\mathrm{RxDX}$ & 8 & 10 & 31 & 00 & 07 & ff & 00 & 02 & 00 \\
\hline 55355.71 & $0 \times 1 \operatorname{cecf} 456$ & $\mathrm{RxDX}$ & 8 & 11 & 07 & 01 & ff & ff & 00 & 02 & 00 \\
\hline 55358.31 & $0 \times 1$ ceb56f 4 & $\mathrm{RxDX}$ & 8 & 01 & 01 & 01 & 00 & 03 & $3 c$ & 00 & $4 c$ \\
\hline 55369.61 & $0 \times 1$ ceb56f 4 & $\mathrm{RxDX}$ & 8 & 02 & $1 d$ & ff & ff & ff & ff & ff & ff \\
\hline 55380.91 & $0 \times 1$ ceb56f 4 & $\mathrm{RxDX}$ & 8 & 03 & ff & ff & ff & ff & ff & ff & ff \\
\hline 55392.21 & $0 \times 1$ ceb5 $6 f 4$ & $\mathrm{RxDX}$ & 8 & 04 & ff & ff & ff & ff & ff & ff & ff \\
\hline 55403.51 & $0 \times 1$ ceb56f4 & $\mathrm{RxDX}$ & 8 & 05 & ff & ff & ff & ff & ff & ff & ff \\
\hline 55414.71 & $0 \times 1$ ceb56f4 & $\mathrm{RxDX}$ & 8 & 06 & ff & ff & ff & ff & ff & ff & ff \\
\hline 55426.01 & $0 \times 1$ ceb56f 4 & $\mathrm{RxDX}$ & 8 & 07 & ff & ff & ff & ff & ff & ff & ff \\
\hline 55430.71 & $0 \times 1 \operatorname{cecf} 456$ & $\mathrm{RxDX}$ & 8 & 13 & 31 & 00 & 07 & ff & 00 & 02 & 00 \\
\hline 55545.61 & $0 \times 182756 f 4$ & $\mathrm{RxDX}$ & 2 & $4 c$ & 1d & & & & & & \\
\hline 55595.71 & $0 \times 1801 f 456$ & $\mathrm{RxDX}$ & 8 & aa & ff & ff & ff & ff & ff & ff & ff \\
\hline 55596.31 & $0 \times 1808 \mathrm{f} 456$ & $\mathrm{RxDX}$ & 8 & $4 c$ & 1d & $\mathrm{b} 8$ & $\mathrm{Ob}$ & 10 & Oe & $8 c$ & $0 f$ \\
\hline 55617.61 & $0 \times 1 \operatorname{cec} 56 f 4$ & $\mathrm{RxDX}$ & 8 & 10 & od & 00 & 02 & ff & 00 & 06 & 00 \\
\hline 55625.61 & $0 \times 1$ cecf 456 & $\mathrm{RxDX}$ & 8 & 11 & 02 & 01 & ff & ff & 00 & 06 & 00 \\
\hline 55628.81 & $0 \times 1$ ceb56f 4 & $\mathrm{RxDX}$ & 8 & 01 & $f 4$ & 01 & $\mathrm{do}$ & 07 & 32 & 00 & $4 c$ \\
\hline 55640.11 & $0 \times 1$ ceb56f4 & $\mathrm{RxDX}$ & 8 & 02 & $1 d$ & 64 & 64 & 00 & $\mathrm{co}$ & 12 & ff \\
\hline 55655.61 & $0 \times 1 \operatorname{cecf} 456$ & $\mathrm{RxDX}$ & 8 & 13 & $\mathrm{Od}$ & 00 & 02 & ff & 00 & 06 & 00 \\
\hline 55685.61 & $0 \times 1807 f 456$ & $\mathrm{RxDX}$ & 7 & ff & ff & ff & ff & ff & ff & ff & \\
\hline 55806.81 & $0 \times 100956 f 4$ & $\mathrm{RxDX}$ & 1 & aa & & & & & & & \\
\hline 55850.31 & $0 \times 100 a f 456$ & $\mathrm{RxDX}$ & 1 & 00 & & & & & & & \\
\hline 55850.81 & $0 \times 1808 f 456$ & $\mathrm{RxDX}$ & 8 & $4 c$ & $1 d$ & b8 & $\mathrm{Ob}$ & 10 & $\mathrm{Oe}$ & $8 c$ & $0 f$ \\
\hline 56068.21 & $0 \times 100956 f 4$ & $\mathrm{RxDX}$ & 1 & aa & & & & & & & \\
\hline 56105.11 & $0 \times 100$ af 456 & $\mathrm{RxDX}$ & 1 & 00 & & & & & & & \\
\hline 56190.41 & $0 \times 1807 f 456$ & $\mathrm{RxDX}$ & 7 & ff & ff & ff & ff & ff & ff & ff & \\
\hline 56320.41 & $0 \times 1812 \mathrm{f} 456$ & $\mathrm{RxDX}$ & 7 & $5 d$ & $1 \mathrm{~d}$ & $\mathrm{a} 0$ & $0 f$ & 00 & 00 & fc & \\
\hline 56329.61 & $0 \times 100956 \mathrm{f} 4$ & $\mathrm{RxDX}$ & 1 & aa & & & & & & & \\
\hline 56360.01 & $0 \times 100$ af 456 & $\mathrm{RxDX}$ & 1 & aa & & & & & & & \\
\hline 56375.21 & $0 \times 1812 f 456$ & $\mathrm{RxDX}$ & 7 & $5 d$ & $1 \mathrm{~d}$ & $\mathrm{a} 0$ & $0 f$ & 00 & 00 & fc & \\
\hline 56382.01 & $0 \times 181056 \mathrm{f} 4$ & $\mathrm{RxDX}$ & 5 & 88 & 13 & $6 e$ & of & 02 & & & \\
\hline 56430.21 & $0 \times 1812 \mathrm{f} 456$ & $\mathrm{RxDX}$ & 7 & $5 d$ & $1 d$ & $\mathrm{a} 0$ & of & 00 & 00 & fc & \\
\hline 56434.31 & $0 \times 181056 f 4$ & $\mathrm{RxDX}$ & 5 & 88 & 13 & $6 e$ & $0 f$ & 02 & & & \\
\hline 56485.21 & $0 \times 1812 f 456$ & $\mathrm{RxDX}$ & 7 & $5 d$ & $1 d$ & $a 0$ & $0 f$ & 00 & 00 & fc & \\
\hline 56486.61 & $0 \times 181056 \mathrm{f} 4$ & $\mathrm{RxDX}$ & 5 & 88 & 13 & $6 e$ & of & 02 & & & \\
\hline 56538.91 & $0 \times 181056 f 4$ & $\mathrm{RxDX}$ & 5 & 88 & 13 & $6 \mathrm{e}$ & Of & 02 & & & \\
\hline 56540.21 & $0 \times 1812 f 456$ & $\mathrm{RxDX}$ & 7 & $5 d$ & $1 d$ & $a 0$ & $0 f$ & 00 & 00 & fc & \\
\hline 56591.01 & $0 \times 100956 f 4$ & $\mathrm{RxDX}$ & 1 & aa & & & & & & & \\
\hline 56591.51 & $0 \times 181356 f 4$ & $\mathrm{RxDX}$ & 7 & 01 & 64 & 01 & 32 & 01 & 00 & 10 & \\
\hline 56592.11 & $0 \times 1$ cec $56 f 4$ & $\mathrm{RxDX}$ & 8 & 10 & 09 & 00 & 02 & ff & 00 & 11 & 00 \\
\hline 56595.21 & $0 \times 1812 f 456$ & $\mathrm{RxDX}$ & 7 & $5 d$ & $1 d$ & $\mathrm{a} 0$ & $0 f$ & 00 & 00 & fc & \\
\hline 56600.21 & $0 \times 1 \operatorname{cecf} 456$ & $\mathrm{RxDX}$ & 8 & 11 & 02 & 01 & ff & ff & 00 & 11 & 00 \\
\hline
\end{tabular}

Figure 6. Communicate with the dc test system part of the communication.

phase, charging phase, and charge termination phase of the DC test system are reflected [5] [6].

\section{References}

[1] Moore, S.W. and Schneider, P.J. (2001) A Review of Cell Equalization Methods for Lithium Ion and Lithium Polymer Battery Systems. Society of Automotive Engineers, 9, 230-235. https://doi.org/10.4271/2001-01-0959

[2] Moore, S.W. and Schneider, P.J. (2001) A Review of Cell Equalization Methods for Lithium ion and Lithium Polymer Battery Systems. SAE Publication, 2001, 01-0959. https://doi.org/10.4271/2001-01-0959

[3] Baughman, A.C. and Ferdowsi, M. (2008) Double-Tiered Switched-Capacitor Battery Charge Equalization Technique. IEEE Transactions on Industrial Electronics, 55, 2277-2285. https://doi.org/10.1109/TIE.2008.918401

[4] Bazydlo, G., Adamski, M., Wegrzyn, M. and Rosado Munoz, A. (2013) From UML State Machine Diagram into FPGA Implementation. IFAC Proceedings Volumes, 46, 231-235. https://doi.org/10.3182/20130925-3-CZ-3023.00061

[5] Panov, Y. and Jovanovic, M.M. (2008) Loop Gain Measurement of Paralleled 
DC-DC Converters with Average-Current-Sharing Control. IEEE Transactions on Power Electronics, 23, 2942-2948. https://doi.org/10.1109/TPEL.2008.2002955

[6] Cheng, D.K.W, Lee, Y.S. and Chen, Y. (2005) A Current-Sharing Interface Circuit with New Current-Sharing Technique. IEEE Transactions on Power Electronics, 20, 35-43. https://doi.org/10.1109/TPEL.2004.839875 